\title{
Influencing Analysis of Ply Parameters to Blade Properties based on Response Surface Method
}

\author{
Penghui $\mathrm{Wu}^{\mathrm{a}, \mathrm{b}}$, Pengwen Sun ${ }^{\mathrm{a}, \mathrm{b}, *}$, Jinghua $\mathrm{Cao}^{\mathrm{a}}$, and Lanting Zhang ${ }^{\mathrm{a}}$ \\ ${ }^{a}$ College of Mechanical Engineering, Inner Mongolia University of Technology, Hohhot, 010051, China \\ ${ }^{b}$ Key Laboratory for Wind and Solar Power Energy Utilization Technology, Ministry of Education and Inner Mongolia Construction, \\ Hohhot, 010051, China
}

\begin{abstract}
The performance of a composite wind turbine blade varies with its ply parameters. According to the design principle of the response surface method, different ply schemes are built. Taking the optimal overall properties of the blade as goals, with ply parameters as independent variables and the static strength and stiffness of the blade as response variables, experiments are designed using the Taguchi method in Minitab, and the static strength and stiffness of the blade are simulated. The mapping relationship between ply parameters and the Tsai-Wu failure factor is determined, the maximum displacement is established through multivariate linear regression analysis, and the significant test of the mathematical model and its coefficients is performed. The influence of ply parameters on blade structure performance is analyzed. The correctness and effectiveness of the method are verified.
\end{abstract}

Keywords: ply parameters; structural properties; coupling influence; response surface method; wind turbines

(Submitted on October 11, 2018; Revised on November 15, 2018; Accepted on December 8, 2018)

(C) 2019 Totem Publisher, Inc. All rights reserved.

\section{Introduction}

The wind turbine blade is the critical component of capturing wind energy, and the force born by the blade is extremely complex. Its structure property directly affects the safety and reliability operation of the wind turbine [1]. Blade property depends not only on the performance of composite fiber, but also on the selection and control of the molding method and forming parameters [2]. The main laminate parameters of the blade are the laminating angle, ply thickness, and stacking sequence. The main characteristic parameters measuring blade structure property include strength, stiffness, fatigue strength, and stability. Many research works have shown that laminate parameters determine blade property, which has an important effect on blade performance. However, what is the rule of this effect? It is still unclear what kind of mapping relationship exists between laminate parameters and characteristic parameters of blade property. Many cases mainly rely on experiential methods of trial grope.

In the research of this area, Zhang et al. studied the influence of single laminate parameter on the static structural performance of the blade by analysing and comparing the representative laminating schemes of different ply parameters [3]. Xie et al. studied the blade laminate structure based on the experimental design method, and the results showed that the $0^{\circ}$ and $\pm 45^{\circ}$ fiber layer had a coupling effect on blade strength [4]. Deng analysed and studied the multi-parameter optimization of wind turbine blades based on the response surface method [5]. Liu et al. used the response surface optimization method to analyse and study the failure probability of bionic wind turbine blades under different ply angles [6]. Aized et al. analysed and optimized the automatic fiber placement process based on the response surface method [7]. It can be seen that the relevant studies are relatively scattered and simple, and the mapping relationship between ply parameters and the structural performance of the blade has not yet been established.

The finite element method based on numerical simulation technology has been widely used in the structural performance analysis of composite materials [8]. The response surface method is an effective method to solve the mapping

* Corresponding author.

E-mail address: pwsun@imut.edu.cn 
relationship between factors and response variables by setting up a finite number of test times, meeting the requirements, and constructing a mathematical model [9-10]. Therefore, from an engineering viewpoint, the first-order coupling relationship between the laminate parameter and the blade property will be established by adopting a combination of the finite element method and the response surface method, and the macroscopic influence of the ply parameters on the blade structure performance will be explored in this paper.

\section{Wind Turbine Blade Model and Test Scheme}

Take a certain $1.5 \mathrm{MW}$ wind turbine blade as the research object, which is a typical representation. This blade adopts Aerodyn and NACA modified airfoil. The length of the blade is $40.3 \mathrm{~m}$, and the diameter of the wind wheel is $82.5 \mathrm{~m}$. The maximum string length is $3.183 \mathrm{~m}$, and the rated rotational speed is $17.4 \mathrm{rpm}$. The blade structure is the main beam and double web, which consists of inner and outer skin, main beam and double web, and so on [11]. The blade is divided into three segments along its span direction, namely the anterior segment, the middle segment, and the root part. The root part, from 0 to $1 / 3$ of the blade root, is the place where blade bears the maximum load. As the blade bears a sustained load during the operating process, the middle segment, which is from $1 / 3$ to $2 / 3$ of the blade root, should have enough strength and stiffness. Since most of the loads are concentrated in the root part and middle part, the two-third part $(0 \sim 28.75 \mathrm{~m})$ of the blade root is taken as the study object. An equivalent concentrated force and bending moment loads in three directions are applied at the center of each force section of the blade, and the six degrees of freedom in the root part are complete restrained. The final finite element model of the blade is shown in Figure 1, and it has 132781 units and 65772 nodes.

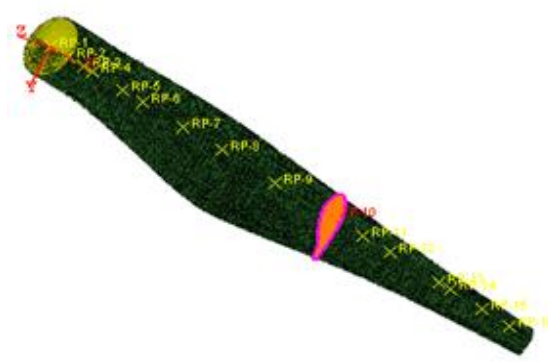

Figure 1. Finite element model of 1.5MW wind turbine blade

According to the anisotropy of composite, the design criterion of the composite laminated plate, engineering practice, and experience, the laminate angles are from $30^{\circ}$ to $50^{\circ}$, the $0^{\circ}$ layer thickness ratio is from $10 \%$ to $40 \%$, and three representative and regular stacking sequence are determined as the study scope, as shown in Table 1 . In order to improve the overall resistance to tension and compression of the blade, a $0^{\circ}$ or $90^{\circ}$ unidirectional fiber cloth should be properly placed.

Table 1 . Test scheme of blade's ply parameters

\begin{tabular}{|c|c|c|}
\hline Laminate angle & $0^{\circ}$ ply thickness ratio & Stacking sequence \\
\hline $30^{\circ}$ & $10 \%$ & {$\left[ \pm x^{\circ} /\left(0^{\circ}, \pm x^{\circ}\right)_{2} / \pm x^{\circ} /\left(0^{\circ}, \pm x^{\circ}\right)_{2}\right]_{\mathrm{NT}}$} \\
\hline $45^{\circ}$ & $30 \%$ & {$\left[\left(0^{\circ}, \pm x^{\circ}\right)_{2} /\left( \pm x^{\circ}\right)_{2} /\left(0^{\circ}, \pm x^{\circ}\right)_{2}\right]_{\mathrm{NT}}$} \\
\hline $50^{\circ}$ & $40 \%$ & {$\left[\left( \pm x^{\circ}\right) /\left(0^{\circ}, \pm x^{\circ}\right)_{4} /\left( \pm x^{\circ}\right)\right]_{\mathrm{NT}}$} \\
\hline
\end{tabular}

\section{First Order Design of Ply Parameters and Blade Static Performance based on Response Surface Method}

\subsection{The Design Flow of First-Order Response Surface}

According to the test scheme, the test is designed based on the Taguchi design method in Minitab Software. In ABAQUS, the structural static strength and stiffness of each test scheme will be analysed. The data are processed by multivariate linear regression analysis, and the regression coefficient can be estimated. Thus, the first-order linear mapping relationship between the ply parameters and the single property parameter of the blade is obtained. The significance of the regression coefficient and regression equation is tested to determine whether the mathematical model is usable, and the influence degree of the factors on the response value is identified. The influence law of the ply parameters on the single performance of the blade will be explored. The design flow is shown in Figure 2. 


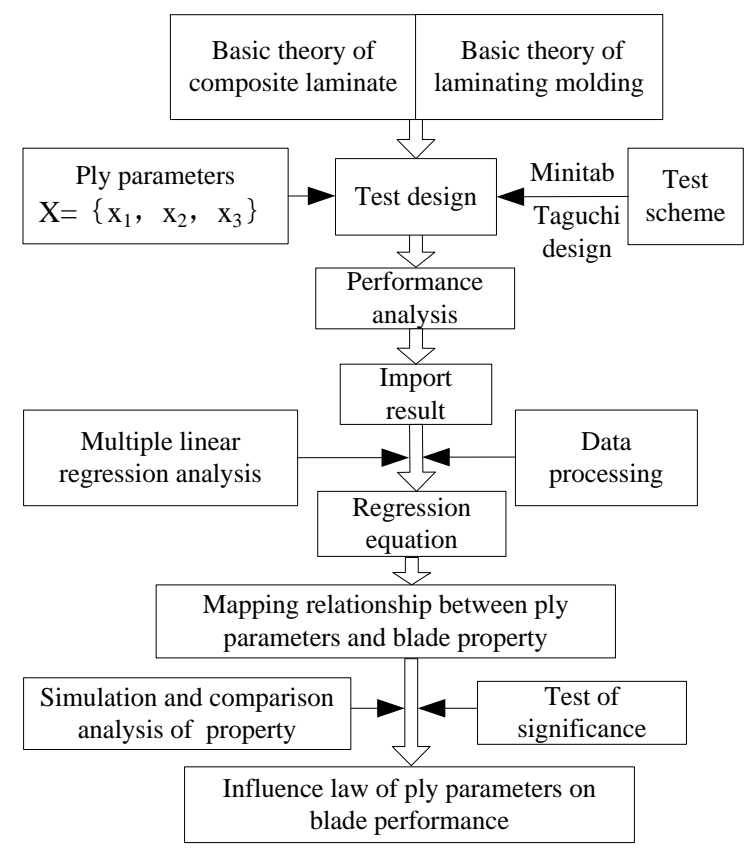

Figure 2. Design flow of the response surface method

\subsection{Response Surface Model and Significance Test}

Take the first-order design method of response surface to establish the mapping relationship between ply parameters and the static strength and stiffness of the blade [12-13]. The equation is given as

$$
y=\beta_{0}+\sum_{i=1}^{m} \beta_{i} x_{i}+\varepsilon
$$

Where $y$ is the response variable, $x_{i}$ is the independent variable, $\varepsilon$ is the normal random error, $\beta_{0}$ is the regression intercept, $\beta_{i}$ is regression coefficient, and $m$ is the number of independent variables.

After establishing the regression equation, it is necessary to test its significance, decide whether the mathematical model is usable, and determine the influence degree of the factors on the response value.

The significance test of the response surface equation is given as:

$$
F=\frac{U / f_{u}}{Q_{E} / f_{Q E}}
$$

Where $F$ is the confidence level of the response surface equation, $U$ is the square sum of regression, $f_{U}$ is the degree of freedom, $Q_{E}$ is the square sum of residual, and $f_{Q E}$ is the corresponding degree of freedom.

Taking $F_{\alpha}(\alpha=0.05)$ as the reference standard of the significance test, if $F>F_{\alpha}\left(f_{U}, f_{Q E}\right)$, the response surface equation is meaningful. Otherwise, the response surface equation is not significant, which has little value when studying the laws between factors and variables [2].

The significance test of regression coefficient is the following:

$$
F_{i}=\frac{U_{i}}{\bar{Q}_{E}}, i=1,2, \cdots, m
$$


If $F_{i}>F_{\alpha}\left(1, f_{Q E}\right)$, the factor $x_{i}$ in the response surface equation is significant, and it has greater influence on the static structural performance of the blade. Otherwise, this factor has no significant influence.

\subsection{Establishing the First-Order Linear Mapping Relationship Between Ply Parameters and the Strength and Stiffness of the Blade}

The test scheme of three factors and two levels is designed by means of the Taguchi design method in Minitab soft. The static strength and stiffness of the blade are analysed in ABAQUS. The test scheme and analysis results are shown in Table 2.

Due to limited space, only the results of test 2 and test 8 are given, as shown in Figure 3 and Figure 4 respectively.

Table 2. Test scheme and analysis result

\begin{tabular}{|c|c|c|c|c|c|}
\hline Test No. & Layer angle & $0^{\circ}$ ply thickness ratio & Stacking sequence & Tsai-Wu failure factor & Maximum displacement (mm) \\
\hline 1 & $50^{\circ}$ & $40 \%$ & 3 & 0.8028 & 877.6 \\
\hline 2 & $50^{\circ}$ & $40 \%$ & 1 & 0.8017 & 882.5 \\
\hline 3 & $50^{\circ}$ & $10 \%$ & 3 & 0.8940 & 991.1 \\
\hline 4 & $50^{\circ}$ & $10 \%$ & 1 & 0.8659 & 991.4 \\
\hline 5 & $30^{\circ}$ & $40 \%$ & 3 & 0.8016 & 873.6 \\
\hline 6 & $30^{\circ}$ & $40 \%$ & 1 & 0.8053 & 873.0 \\
\hline 7 & $30^{\circ}$ & $10 \%$ & 3 & 0.8872 & 987.8 \\
\hline 8 & $30^{\circ}$ & $10 \%$ & 1 & 0.9044 & 988.1 \\
\hline
\end{tabular}

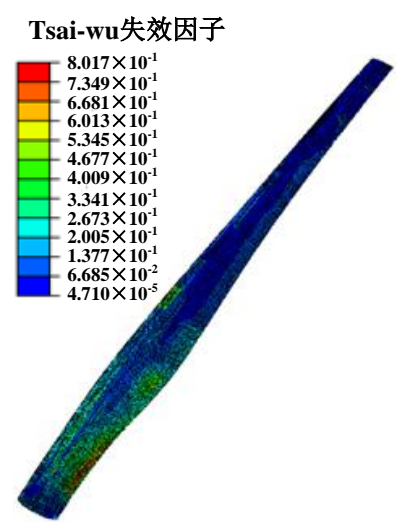

(a)

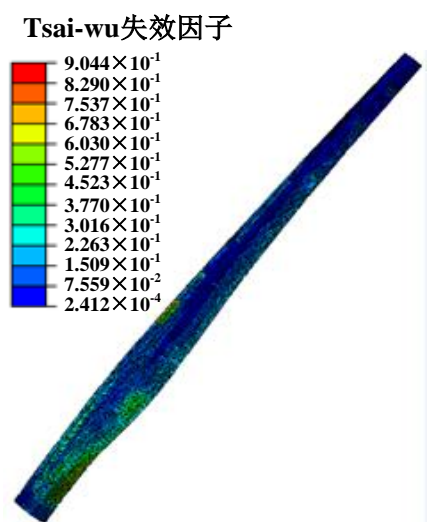

(b)

Figure 3. (a) Tsai-Wu failure factor of test 2; (b) Tsai-Wu failure factor of test 8

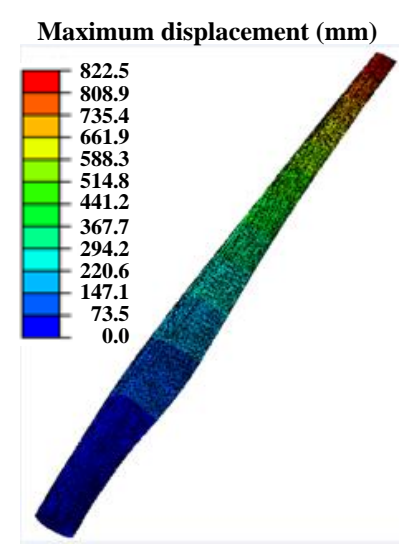

(a)

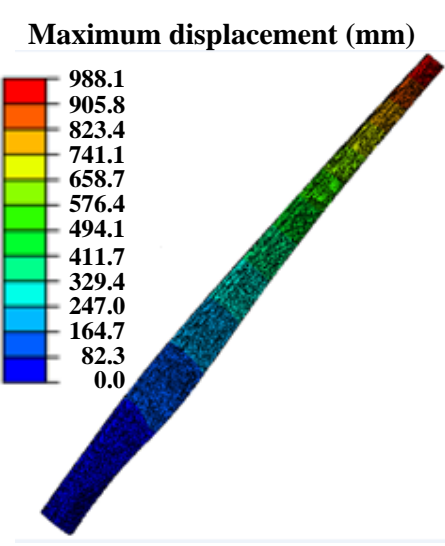

(b)

Figure 4. (a) maximum displacement of test 2; (b) maximum displacement of test 8

According to the test results, each regression coefficient is estimated by means of the least squares method in regression analysis, and the first-order linear mapping relationship between ply parameters, the Tsai-Wu failure factor, and the maximum displacement is obtained respectively. 


$$
\begin{gathered}
y_{1}=0.8659-0.0004 x_{1}-0.0028 x_{2}+0.0010 x_{3} \\
y_{2}=925.25+0.25 x_{1}-3.76 x_{2}-0.61 x_{3}
\end{gathered}
$$

Where $y_{1}$ is the Tsai-Wu failure factor, $y_{2}$ is the maximum displacement, $x_{1}$ is the laminate angle, $x_{2}$ is the $0^{\circ}$ ply thickness ratio, and $y_{3}$ is the stacking sequence.

The significance test of the first order response surface equation between ply parameters and blade strength is given as follows.

Through calculation, $U=0.015, f_{U}=m=3, Q_{E}=0.00065$, and $f_{Q E}=8-3-1=4$.

Then,

$$
F_{y 1}=\frac{U / f_{U}}{Q_{E} / f_{Q E}}=\frac{0.015 / 3}{0.00065 / 4}=30.03>F_{0.05}(3,4)=6.59
$$

This shows that the response surface equation of the Tsai-Wu failure factor is significant and usable.

Through calculation,

$$
U_{1}=0.00015, U_{2}=0.0145, U_{3}=0.00001, \bar{Q}_{E}=\frac{Q_{E}}{f_{E}}=0.00065 / 4=0.000162
$$

To $\alpha=0.05$, through look-up table [4]: $F_{0.05}(1,4)=7.71$. Then,

$$
\begin{aligned}
& F_{1}=\frac{0.00015}{0.000162}=0.90<F_{0.05}(1,4) \\
& F_{2}=\frac{0.0145}{0.000162}=89.13>F_{0.05}(1,4) \\
& F_{3}=\frac{0.00001}{0.000162}=0.05<F_{0.05}(1,4)
\end{aligned}
$$

The $0^{\circ}$ ply thickness ratio has significant influence on the static strength of the blade, and the influence of the laminate angle and stacking sequence is not significant.

In the same way, the significance test of the first order response surface equation between ply parameters and blade stiffness is given as follows.

Through calculation, $U=25558, f_{U}=m=3, Q_{E}=15.2$, and $f_{Q E}=8-3-1=4$.

Then,

$$
F_{U}=\frac{U / f_{U}}{Q_{E} / f_{Q E}}=\frac{25558 / 3}{15.2 / 4}=2238.21>F_{0.05}(3,4)=6.59
$$

This shows that the response surface equation of the maximum displacement is significant and usable. 
Through calculation,

$$
\begin{gathered}
U_{1}=50.5, U_{2}=25504.1, U_{3}=3.0, \bar{Q}_{E}=\frac{Q_{E}}{f_{E}}=15.2 / 4=3.8 \\
F_{1}=\frac{50.5}{3.8}=13.27>F_{0.05}(1,4) \\
F_{2}=\frac{25504.1}{3.8}=6700.59>F_{0.05}(1,4) \\
F_{3}=\frac{3.0}{3.8}=0.79<F_{0.05}(1,4)
\end{gathered}
$$

The laminate angle and $0^{\circ}$ layer thickness ratio has significant influence on the static stiffness of the blade, and the influence of stacking sequence is not significant.

\section{Influence Analysis of Ply Parameters on the Blade Structure Property}

\subsection{The Macroscopic Influence of Ply Parameter on Static Strength of the Blade}

It can be seen from Eq. (4) that when the stacking sequence is unchanged, with a gradual increase in the laminate angle and $0^{\circ}$ ply thickness ratio, the Tsai-Wu failure factor of the blade decreases and the strength increases.

According to the experimental scheme and analysis results of Table 2 , when the stacking sequence is 1 , the $0^{\circ}$ ply thickness ratio is $10 \%$ and $40 \%$, respectively. The influence of the laminate angle on the static strength of the blade is shown in Figure 5. When the laminate angle increases from $30^{\circ}$ to $50^{\circ}$, the Tsai-Wu failure factor decreases and the blade strength increases. The decreasing degree of the Tsai-Wu failure factor when the $0^{\circ}$ ply thickness ratio is $10 \%$ is faster than that when the $0^{\circ}$ layer thickness ratio is $40 \%$.

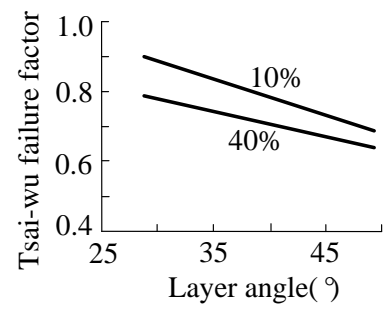

Figure 5. Tsai-Wu failure factor with different laminate angles

When the stacking sequence is 1 and the laminate angle is $30^{\circ}$ and $50^{\circ}$ respectively, the influence of the $0^{\circ}$ ply thickness ratio on the static strength of the blade is shown as in Figure 6 . When the $0^{\circ}$ ply thickness ratio increases from $10 \%$ to $40 \%$, the Tsai-Wu failure factor decreases and the blade strength increases. The decreasing degree of the Tsai-Wu failure factor when the laminate angle is $30^{\circ}$ is faster than that when the laminate angle is $50^{\circ}$.

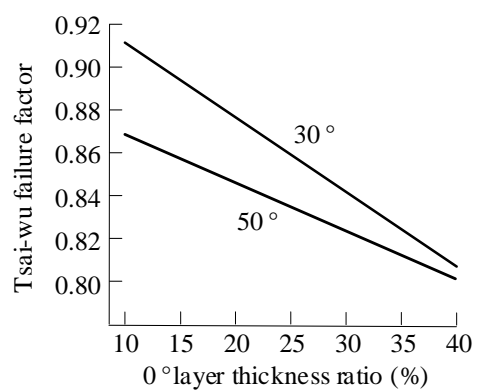

Figure 6. Tsai-Wu failure factor with different $0^{\circ}$ ply thickness ratios 
When the laminate angle is $30^{\circ}$, the $0^{\circ}$ ply thickness ratio is $10 \%$ and $40 \%$ respectively, and the influence of different stacking sequences on the static strength of the blade is shown in Figure 7. When the stacking sequence changes from 1 to 3 , the Tsai-Wu failure factor decreases and the blade strength increases. The decreasing degree of the Tsai-Wu failure factor when the $0^{\circ}$ ply thickness ratio is $10 \%$ is faster than that when the $0^{\circ}$ layer thickness ratio is $40 \%$.

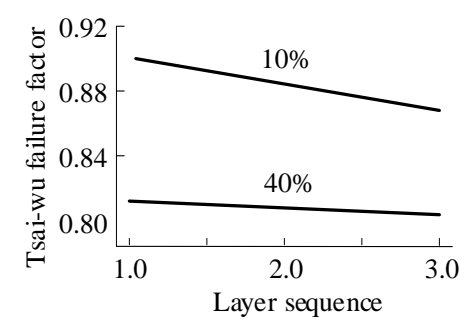

Figure 7. Tsai-Wu failure factor with different stacking sequences

In summary, the greater the slope, the more obvious the influence degree. The influence degree of each factor on the static strength of wind turbine blade is different. Among them, the influence of the $0^{\circ}$ ply thickness ratio is the greatest, followed by the laminate angle, and the stacking sequence has the least influence.

\subsection{The Macroscopic Influence of Ply Parameter on Static Stiffness of the Blade}

It can be seen from Equation (5) that when the stacking sequence remains the same, when the $0^{\circ}$ ply thickness ratio gradually increases, the maximum displacement of the blade decreases and the strength increases. The stiffness of the blade decreases slightly as the laminate angle increases.

According to the experimental scheme and analysis results in Table 2, when the stacking sequence is 1 , the $0^{\circ}$ ply thickness ratio is $10 \%$ and $40 \%$ respectively, and the influence of the laminate angle on the static stiffness of the blade is shown in Figure 8. When the laminate angle increases from $30^{\circ}$ to $50^{\circ}$, the maximum displacement increases and the blade stiffness decreases. The increasing degree of the maximum displacement when the $0^{\circ}$ ply thickness ratio is $10 \%$ is slower than that when the $0^{\circ}$ layer thickness ratio is $40 \%$.

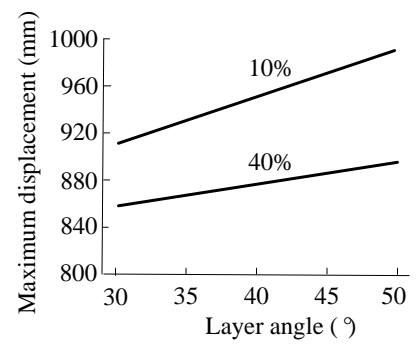

Figure 8 . The maximum displacement with different laminate angles

When the stacking sequence is 1 and the laminate angle is $30^{\circ}$ and $50^{\circ}$ respectively, the influence of the $0^{\circ}$ ply thickness ratio on the static stiffness of the blade is shown in Figure 9 . When the $0^{\circ}$ ply thickness ratio increases from $10 \%$ to $40 \%$, the maximum displacement decreases and the blade stiffness increases. The decreasing degree of the maximum displacement when the laminate angle is $30^{\circ}$ is faster than that when the laminate angle is $50^{\circ}$.

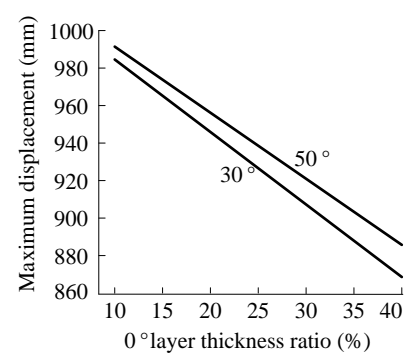

Figure 9. The maximum displacement with different $0^{\circ}$ ply thickness ratios 
When the laminate angle is $30^{\circ}$, the $0^{\circ}$ ply thickness ratio is $10 \%$ and $40 \%$ respectively, and the influence of different stacking sequences on the static stiffness of the blade is shown in Figure 10. When the stacking sequence changes from 1 to 3 , the maximum displacement is basically invariant, and there is almost no influence of the stacking sequence on the blade stiffness. The decreasing degree of the maximum displacement when the $0^{\circ}$ ply thickness ratio is $10 \%$ is slightly faster than that when the $0^{\circ}$ layer thickness ratio is $40 \%$.

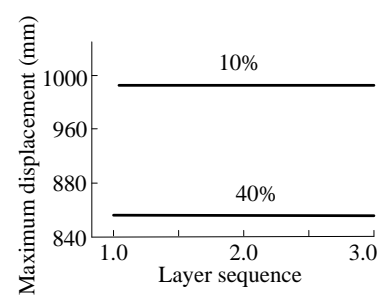

Figure 10. The maximum displacement with different stacking sequences

Overall, the influence degree of each factor on the static stiffness of the blade is different. Among them, the influence of the $0^{\circ}$ ply thickness ratio is the greatest, followed by the laminate angle, and the stacking sequence has the least influence.

\section{Conclusions}

Ply parameters have important influence on the property of wind turbine blades. From an engineering viewpoint, according to the design principle of the first-order response surface and Taguchi design method, the test scheme of ply parameters is designed, and the static strength and stiffness of the blade are simulated. The coefficient is estimated by the least squares method in regression analysis, and the first order linear mapping relationship between ply parameters, the Tsai-Wu failure factor, and the maximum displacement are established. The significance test is performed, and the influence of ply parameters on blade structure property is analysed. The results show that the influence of the laminate angle is not significant on blade strength and is significant on stiffness. The influence of the $0^{\circ}$ ply thickness ratio on blade strength and stiffness are both significant, and the influence of the stacking sequence on blade strength and stiffness are not significant. The influence degree of each ply parameter on the static strength and stiffness of wind turbine blades is different. The influence of the $0^{\circ}$ ply thickness ratio is the greatest, the laminate angle is the second greatest, and the stacking sequence has the least influence. The first regression model is suitable for this test, the method is feasible and effective, and the research has practical reference value.

\section{Acknowledgements}

The work is supported by the National Natural Science Foundation of China (No. 51665046), Foundation of Key Laboratory for Wind and Solar Power Energy Utilization Technology, Ministry of Education and Inner Mongolia Construction (No. 201606), and Caoyuan Elite Engineering of the Inner Mongolia Autonomous Region.

\section{References}

1. Y. Hu, J. Dai, and D. Liu, "Research Status and Development Trend on Large Scale Wind Turbine Blades," Journal of Mechanical Engineering, Vol. 49, No. 20, pp. 140-151, October 2013

2. S. N. Sørensen and M. Stolpe, "Global Blending Optimization of Laminated Composites with Discrete Material Candidate Selection and Thickness Variation," Structural and Multidisciplinary Optimization, Vol. 52, No. 1, pp. 137-155, January 2015

3. L. Zhang, H. Deng, and J. Gao, "Influencing Analysis on Lamination Parameters to Static Structure Performance of Wind Turbine Blade," Acta Energiae Solaris Sinica, Vol. 35, No. 6, pp. 1059-1064, June 2014

4. L. Zhang, S. Li, P. Sun, and M. Zhu, "Coupling Effects Analysis of Laminating Parameter to Structural Properties of Wind Turbine Blade,” Acta Energiae Solaris Sinica, Vol. 39, No. 6, pp. 1768-1774, June 2018

5. L. Deng, Z. D. Qiao, W. P. Song, and Y. W. Gao, "Optimizing Design Research of Wind Turbine Blade based on Response Surface Methodology," Acta Aero Dynamica Sinica, Vol. 30, No. 3, pp. 405-410, March 2012

6. P. Sun, Z. Xing, and H. Wang, "Study on Optimization Design of Wind Turbine Blade with Composite Fiber Lamination Structure," Acta Energiae Solaris Sinica, Vol. 36, No. 6, pp. 1410-1417, June 2015

7. L. Li, S. Zhang, and Q. He, "Application of Response Surface Methodology in Experiment Design and Optimization," Research and Exploration in Laboratory, Vol. 34, No.8, pp. 41-45, August 2015

8. H. Bin, Y. Usui, K. Takaki, and T. Kanemoto, "Optimization of Blade Setting Angles of a Counterrotating Type Horizontal Axis Tidal Turbine using Response Surface Methodology and Experimental Validation," International Journal of Energy Research, Vol. 40, No. 5, pp. 610-617, May 2016 
9. E. Lund, "Discrete Material and Thickness Optimization of Laminated Composite Structures Including Failure Criteria," Structural and Multidisciplinary Optimization, Vol. 56, No. 12, pp. 1-19, December 2017

10. R. Yang, Z. Zhang, Y. Liu, Z. Wu, and G. Wang, "The Effect of the Beam Ply Parameters on Structure Performance of Wind Turbine Blade," Journal of Sichuan University of Science \& Engineering, Vol. 29, No. 5, pp. 27-32, May 2016

11. Y. Shi, T. Yu, X. He, C. Kang, X. Zhang, and J. Zhang, "Mechanism and Optimization of Process Parameters Coupling for Composite Tape Winding,” Acta Materiae Compoaitae Sinca, Vol. 32, No. 3, pp. 831-838, March 2015

12. W. He, W. Xue, and B. Tang, "Optimal Method of Test Design and Data Analysis," Chemical Industry Press, September 2016

13. C. Y. Kiyono, E. C. N. Silva, and J. N. Reddy, "A Novel Fiber Optimization Method based on Normal Distribution Function With Continuously Varying Fiber Path,” Composite Structures, Vol. 160, pp. 503-515, January 2017 